\title{
ANALISIS KELAYAKAN LAHAN BUDIDAYA RUMPUT LAUT GRACILARIA sp DI TAMBAK KECAMATAN SINJAI UTARA KABUPATEN SINJAI
}

Analysis of Seaweed Gracilaria sp. Culture on Shrimp Farms Land Suitability in District, Sinjai.

\author{
Agustang $^{1}$, Sri Mulyani ${ }^{2}$, Erni Indrawati ${ }^{2}$ \\ ${ }^{1}$ Dinas Kelautan dan Perikanan Kabupaten Sinjai \\ ${ }^{2}$ Program Studi Budidaya Perairan Program Pascasarjana Universitas Bosowa
}

Email: agustang_ag@yahoo.co.id

Diterima : 30 Oktober 2019

Dipublikasikan : 09 Desember 2019

\begin{abstract}
ABSTRAK
Rumput laut Gracilaria sp merupakan sumber pangan dan memiliki nilai ekonomis tinggi sebagai sumber devisa serta usaha padat karya yang mampu menyerap banyak tenaga kerja. Penelitian ini bertujuan untuk mengetahui karakteristik dan tingkat kelayakan lahan tambak untuk budidaya rumput laut (Gracilaria sp) berdasarkan parameter fisika (Suhu, ,kedalaman dan kecerahan) dan kimia (salinitas, pH, oksigen terlarut, CO2,nitrat dan fosfat). Populasi dalam penelitian ini adalah kawasan tambak yang ada di Kecamatan Sinjai Utara Kabupaten Sinjai, sampelnya sebanyak 3 titik/stasiun pengamatan ditentukan dengan menggunakan metode purposive sampling berdasarkan letak dan sumber air tambak. Data hasil penelitian diperoleh dengan pengamatan, pengukuran langsung dilapangan(suhu, salinitas, kedalaman, kecerahan, oksigen terlarut dan $\mathrm{pH}$ ) dan analisis laboratorium (fosfat, nitrat,) kemudian dianalisis dengan menggunakan metode pembobotan. Setelah diperoleh nilai skor dari setiap parameter pada setiap titik pengamatan, kemudian dilakukan penilaian yakni layak (S1) dengan kisaran nilai 68-87, cukup layak (S2) dengan kisaran nilai 48-67, dan tidak layak (N) dengan kisaran nilai 27-47.Hasil diperoleh bahwa ketiga stasiun masuk kategori cukup layak (S2) dengan nilai stasiun I (63), stasiun II (56) dan stasiun III (63). Dengan demikian kegiatan budidaya rumput laut Gracillaria sp cukup layak untuk dikembangkan di Kecamatan Sinjai Utara.
\end{abstract}

Kata Kunci : Kelayakan Tambak, Rumput Laut Gracilaria sp.

\section{ABSTRACT}

Seaweed Gracilaria sp is a source of food and having economic value high as a source of foreign exchange and efforts labor-intensive capable of absorbing a lot of labor. Research aims to understand the characteristics and the feasibility land farms to seaweed cultivation (gracilaria sp) based on physical parameters (temperature, deepness and brightness) and chemistry (salinitas , pH, oxygen dissolved,carbon dioxide, nitrate and phosphate). Population in this study of the farms in Sinjai sub district north, sample as many as 3 points/an observation station determined by using the method purposive sampling based on the layout and water sources farms. The data the results of the study obtained with the observation, the measurement of directly field (the temperature of, salinitas, depth, brightness, oxygen dissolved and $\mathrm{pH}$ ) and an analysis of lab where internal conditions (phosphate, nitrate) then analyzed in order by using the method the weightings of the. After the recent retrieval of the value of a score of every parameter on each the point of observation, then be a assessment of bond issuance will be worthy of (s1) with a range of the value of 68-87, seemed worthy enough to operate ( 22$)$ with a range of the value of 48-67, but it is not suitable $(n)$ with a range of the value of 27-47. Result obtained that all three renovation of the gas station is categorized as a seemed worthy enough to operate ( $s 2$ ) with a value of up the first three months of station ( 63 ), renovation of the gas station II ( 56 ) and train stations III (63). As a result of this activities are to be implemented seaweed cultivation gracillaria sp seemed worthy enough to operate to be developed in Sinjai sub district north.

Keywords: farms feasibility, seaweed gracilaria sp .

\section{PENDAHULUAN}

Rumput laut atau seaweed merupakan salah satu tumbuhan laut yang tergolong dalam makroalga benthik atau benthic algae yang hidupnya melekat di dasar perairan. Tanaman ini tidak bisa dibedakan antara bagian akar, batang, dan daun, sehingga bagian tumbuhan tersebut disebut thallus, oleh karena itu tergolong tumbuhan tingkat rendah (Anggadiredja dkk., 2008).

Salah satu daerah di Sulawesi Selatan yang mempunyai potensi produksi rumput laut Gracilaria adalah Kabupaten Sinjai. Kabupaten Sinjai terletak di pesisir timur Sulawesi Selatan yang memiliki luas wilayah $4.559 \mathrm{~km}^{2}$ dengan panjang garis pantai $138 \mathrm{~km}$ dan mempunyai 10 Desa/kelurahan pesisir, dengan areal pertambakan seluas 628,33 hektar ( Statistik DKP,2017). Pesisir pantai Kabupaten Sinjai cocok untuk budidaya rumput laut
Eucheuma cottoni dan areal pertambakan cocok untuk budidaya rumput laut Gracilaria. (Anonim, 2007). Kecamatan Sinjai Utara merupakan salah satu kecamatan di Kabupaten Sinjai yang memiliki potensi areal budidaya rumput laut seluas 317,14 hektar( Statistik DKP, 2017).

Pesatnya perkembangan budidaya rumput laut Glasillaria di tambak kecamatan sinjai utara berpengaruh terhadap peningkatan produksi rumput laut Glasillaria sp. Seiring dengan perkembangan di tambak adanya permasalahan yaitu pertumbuhan rumput laut yang lambat. Salah satu bahkan berpengaruh terhadap pertumbuhan adalah salinitas air, linkungan budidaya baik faktor fisik maupun kimia.

Gracilaria sp merupakan salah satu jenis rumput laut yang sangat potensial untuk dikembangkan, Menurut Sugiyanto dkk, (2013) permintaan agar-agar di Indonesia 
semakin meningkat tiap tahunnya, oleh karena itu pengembangan usaha budidaya Gracilaria sp akan berpotensi menghasilkan keuntungan yang besar. Permintaan pasar tersebut tiap tahunnya mencapai $21,8 \%$ namun pemenuhannya belum mencukupi permintaan tersebut, yaitu hanya berkisar $13,1 \%$. Hal tersebut dikarenakan masih rendahnya tingkat produksi Gracilaria verrucosa di Indonesia (Abdan dkk.,2013).

Salah satu bentuk pemanfaatan lahan yang dilakukan oleh masyarakat Kecamatan Sinjai Utara Kabupaten Sinjai adalah sektor tambak polikultur yaitu bandeng dan udang. Menurut Septiawan (2009) kepadatan biomassa dalam populasi menyebabkan terjadinya penutupan bagian tubuh yang lain (self shading), selain itu distribusi spektrum cahaya matahari pada bagian yang ternaungi lebih sedikit dari pada bagian yang terpapar langsung sehingga cahaya yang dimanfaatkan untuk proses pertumbuhan dan fotosintesis sangat rendah. Yang menjadi kendala dalam melakukan usaha pengembangan budidaya rumput laut Gracilaria sp adalah kurangnya data dan informasi mengenai daya dukung atau karakteristik kelayakan tambak sebagai kawasan budidaya rumput laut Gracilaria sp di kawasan tersebut yang memperhatikan aspek fisik ( suhu, kedalaman, kecerahan, , material dasar perairan) dan kimia (salinitas, $\mathrm{pH}$, oksigen teralarut, $\mathrm{CO} 2$, nitrat dan fosfat). Jika terjadi kesalahan dalam pemilihan lokasi budidaya maka produksi rumput laut Gracilaria sp akan menurun. Sehingga berdasarkan uraian tersebut, maka dianggap penting untuk dilakukan suatu Analisis Kelayakan Lahan Budidaya Rumput Laut Gracilaria sp di Tambak Kecamatan Sinjai Utara.

\section{METODE PENELITIAN}

\section{Lokasi dan Waktu Penelitian}

Penelitian ini dilaksanakan pada bulan Juni sampai dengan bulan Juli 2019, di Kecamatan Sinjai Utara, Kabupaten Sinjai, Provinsi Sulawesi Selatan. Pemilihan lokasi ini didasarkan atas pertimbangan bahwa Kecamatan Sinjai Utara merupakan salah satu daerah wilayah pesisir yang memiliki potensi budidaya rumput laut yang cukup baik untuk dikembangkan.

\section{Jenis dan Sumber Data}

Data yang akan digunakan dalam rencana penelitian ini adalah data primer dan data sekunder. Data primer meliputi; data yang di peroleh dari parameter fisika dan parameter kimia, sedangkan data sekunder meliputi data yang di peroleh dari hasil hasil penelitian terdahulu, literaturliteratur penunjang dan beberapa referensi lainnya yang berhubungan dengan lokasi penelitian.

\section{Analisis Data}

Analisis parameter kualitas air meliputi penyusunan matriks kesesuaian yang disusun melalui studi pustaka sehingga dapat diketahui parameter-parameter pembatas yang diperlukan untuk kegiatan budidaya rumput laut Gracilaria sp. Dalam penelitian setiap parameter dibagi dalam tiga kelas, yaitu kelas layak (S1), cukup layak (S2) dan tidak layak (N).Kelas sangat layak diberi skor 3 (tiga), kelas layak diberi skor 2 (dua) dan kelas tidak layak diberi skor 1 (satu).

Nilai skor diperoleh dengan menggunakan persamaan Utoyo et al (2000) sebagai berikut :Nilai skor $=\Sigma$ Skor $\mathrm{x}$
Bobot.Data yang diperoleh dilapangan, diolah dan dianalisis untuk menentukan kelayakan lahan tambak rumput laut Gracilaria sp.

Setelah mengetahui nilai skor untuk setiap parameter pada setiap satasiun maka dilakukandengan penilaian hasil evaluasi dengan menggunakan Tabel 6 untuk menentukan apakah lokasi tersebut layak (S1), cukup layak (S2) dan tidak layak (N) untuk tambak rumput laut Gracilaria sp.Penilaian skor hasil evaluasi diperoleh dengan persamaan yang dikemukakan oleh Nurdin et all adalah sebagai berikut:

$$
C i=\frac{\text { Bobot max. }- \text { bobot } \min }{n}
$$

Dimana : $\mathrm{Ci}=$ Range antar kelas

$$
\mathrm{n}=\text { Jumlah kelas yang direncanakan }
$$

Tabel 1. Sistem penilaian hasil kelayakan Lahan Tambak untuk budidaya rumput laut adalah sebagai berikut

\begin{tabular}{cccl}
\hline No & $\begin{array}{c}\text { Kisaran } \\
\text { Nilai }\end{array}$ & Kelas & \multicolumn{1}{c}{$\begin{array}{c}\text { Penilaian hasil } \\
\text { Evaluasi }\end{array}$} \\
\hline 1 & $68-87$ & $\begin{array}{c}\text { Layak } \\
\text { (S1) }\end{array}$ & $\begin{array}{l}\text { Daerah ini tidak mempunyai } \\
\text { Pembatas (penghambat) yang } \\
\text { berarti }\end{array}$ \\
\hline 2 & $48-67$ & $\begin{array}{c}\text { Cukup } \\
\text { layak } \\
\text { (S2) }\end{array}$ & $\begin{array}{l}\text { Daerah ini mempunyai } \\
\text { pembatas (pengahambat) } \\
\text { yang cukup berarti }\end{array}$ \\
\hline 3 & $27-47$ & $\begin{array}{c}\text { Tidak } \\
\text { layak } \\
(\mathrm{N})\end{array}$ & $\begin{array}{l}\text { Daerah ini mempunyai } \\
\text { pembatas } \\
\text { dengan tingkat sangat berat }\end{array}$ \\
\hline Sumber: Nurdin etall $(2012)$ &
\end{tabular}

Sumber : Nurdin et all (2012)

\section{HASIL DAN PEMBAHASAN}

Kabupaten Sinjai merupakan salah satu dari 24 Kabupaten/Kota yang berada dalam wilayah Propinsi Sulawesi Selatan yang terletak di pesisir timur bagian selatan daratan Sulawesi Selatan yang berhadapan langsung dengan perairan Teluk Bone.Secara Morfologi, daerah ini lebih dari 55,5\% terdiri dari daerah dataran tinggi $(100$ - 500 meter dari permukaan laut). Secara klimatologi terletak pada posisi iklim musim timur dimana bulan basah jatuh antara bulan April sampai Oktober dan bulan kering antara bulan Oktober sampai April.Secara topografi memiliki pantai yang landai, dengan ombak relatif kecil dan arus yang lemah dan memiliki karaketristik untuk kegiatan budidaya perikanan baik budidaya laut maupun budidaya air payau (tambak).

Tabel 2. Potensi Luas Lahan Tambak, Pemanfaatan dan Peluang Pemanfaatan Kecamatan Sinjai

\begin{tabular}{|c|c|c|c|c|}
\hline No & Kelurahan & $\begin{array}{l}\text { Potensi } \\
\text { (Ha) }\end{array}$ & $\begin{array}{c}\text { Pemanfaatan } \\
\text { (Ha) }\end{array}$ & $\begin{array}{c}\text { Peluang } \\
\text { Pemanfaatan } \\
(\mathrm{Ha})\end{array}$ \\
\hline 1 & Balangnipa & 11,13 & 11,1 & 0,12 \\
\hline 2 & Lappa & 306,1 & 261,1 & 45,00 \\
\hline & Total & 317,23 & 272,2 & 45,12 \\
\hline
\end{tabular}
Utara Kabupaten Sinjai

Pada tabel tersebut di atas memperlihatkan bahwa pemanfaatan lahan tambak untuk kegiatan budidaya baru seluas 273,9 hektar dari total potensi luas lahan 348,15 hektar. Artinya masih terdapat peluang atau potensi 
lahan tambak seluas 9,8 hektar yang belum dimanfaatkan secara optimal untuk kegiatan budidaya tambak.

Kondisi lahan tambak yang belum dimanfaatkan tersebut sebagian besar disebabkan karena konstruksinya sudah tidak memungkinkan akibat rusaknya beberapa pematang dan pintu air. Disamping itu, konstruksi tambak saat ini belum ideal untuk tujuan peningkatan status pengelolaan yang lebih tinggi (Semi intensif maupun intesif), karena sebagian besar areal tambak belum memiliki saluran irigasi teknis yang memadai.Sumber air kepetakan-petakan tambak sebagai media pemeliharaan organisme budidaya masih mengadalkan pasokan-pasokan dari petak tambak yang dekat dengan saluran primer, sementara saluran sekunder dan tersiernya belum dimanfaatkan secara optimal.

Organisme air memiliki syarat-syarat lingkungan agar dapat hidup dan tumbuh dengan baik.Semakin sesuai kondisi lingkungan perairan maka akan semakin baik pertumbuhan suatu organisme. Rumput laut Gracillaria sp merupakan salah satu organisme tambak yang memerlukan habitat lingkungan untuk tumbuh dan berkembang biak. Pertumbuhan rumput laut sangat tergantung dari faktorfoktor oseanografi seperti parameter fisika dan kimia air tambak.

Sehingga dalam penelitian ini dilakukan pengukuran kecerahan pada semua stasiun $100 \%$. Suhu pada stasiun I berkisar antara $30,5-30,9^{\circ} \mathrm{C}$, pada stasiun II $34,1-35,6^{\circ} \mathrm{C}$ dan stasiun III $30,1-30,4^{\circ} \mathrm{C}$. Untuk hasil pengukuran kedalaman stasiun I berkisar antara $60-65 \mathrm{~cm}$, pada stasiun II sekitar $60-66 \mathrm{~cm}$, dan stasiun III sekitar $60-$ $62 \mathrm{~cm}$. Salinitas yang terukur selama penelitian pada stasiun I berkisar antara 27,6 - 28,0 ppt, stasiun II berkisar antara 11,9 - 14,9 ppt, dan pada stasiun III berkisar antara 31,1 32,1 ppt. Hasil pengukuran $\mathrm{pH}$ air tambak pada stasiun I antara 8,5 - 8,7, stasiun II antara 9,9 - 10,3, dan stasiun III antara 8,6 - 8,8. Kadar karbondioksida dalam tambak untuk stasiun I berkisar antara 5,31 - 5,33 $\mathrm{mg} / \mathrm{l}$ sedangkan pada stasiun II antara 13,97- $13,98 \mathrm{mg} / \mathrm{l}$ dan stasiun III antara $16,44-16,85 \mathrm{mg} / \mathrm{l}$. Hasil analisa laboratorium untuk fosfat pada stasiun I berkisar antara $0,02-1,01 \mathrm{mg} / \mathrm{l}$, stasiun II $0,01-0,04 \mathrm{mg} / 1$. Sedangkan untuk analisa nitrat pada stasiun I berkisar antara 0,24 - 0,34 mg/l, 0,25 - 0,37 mg/l dan 0,21 - 0,34 pada stasiun II dan Stasiun III guna dalam mengetahui kondisi fisika kimia tambak untuk budidaya rumput laut Gracillaria sp.

\section{Suhu}

Suhu perairan di tambak Kecamatan Sinjai Utara berkisar antara $30,2-35,8{ }^{\circ} \mathrm{C}$.Suhu pada stasiun 1 rata-rata $30,78{ }^{\circ} \mathrm{C}$, rata-rata suhu pada stasiun 2 adalah $35,08 \mathrm{n}^{\circ} \mathrm{C}$, pada stasiun 3 rata-rata $30,20{ }^{\circ} \mathrm{C}$ dan pada stasiun 4 ratarata suhu tambak adalah $31,54{ }^{\circ} \mathrm{C}$. Nilai tersebut cukup tinggi untuk kegiatan budidaya rumput laut meskipun dapat mendukung proses fotosintesis namun dapat menyebabkkan rumput laut menjadi mengecil dan kerdil;

\section{Kecerahan}

Nilai kecerahan yang diukur dengan menggunakan water quality ceker Horiba.Kecerahan perairan pada stasiun 1 rata-rata $45,5 \mathrm{~cm}$, stasiun 2 rata-rata $24,00 \mathrm{~cm}$, stasiun 3 rata-rata 47,8 . Rata-rata nilai dari semua stasiun tersebut masih cukup baik untuk organisme perairan kecuali pada stasiun 2 yang rendah.Ditjenkanbud (2006), menyatakan bahwa nilai kecerahan air yang baik untuk pertumbuhan dan kelangsungan organisme perairan adalah lebih besar dari $45 \mathrm{~cm}$. Ditambahkan oleh Zatnika (2009) bahwa persyaratan lokasi budidaya Gracilaria adalah tidak keruh yakni matahari menembus sampai ke dasar tambak. Rendahnya nilai kecerahan perairan umumnya disebabkan oleh tingginya kekeruhan oleh banyaknya bahan organik terlarut dan tersuspensi, benda-benda terapung dan intensitas cahaya.

\section{Kedalaman}

Rumput laut memerlukan sinar matahari untuk proses fotosintesis, karena itu rumput laut hanya dapat tumbuh pada perairan dengan kedalaman tertentu dimana sinar matahari dapat sampai ke dasar perairan. Kedalam ratarata tambak di Kecamatan Sinjai Utara meliputi stasiun 1 rata-rata kedalaman tambak sekitar 65,62, stasiun 2 diperoleh kedalaman rata-rata sekitar 40,58, pada stasiun 3 didapat rata-rata 60,64. Kedalaman rata-rata semua stasiun masih pada taraf yang menguntungkan pertumbuhan dan perkembangan budidaya rumput laut gracillaria karena pada kedalamn tersebut intensitas cahaya matahari sampai pada rumput laut masih sangat tinggi sehingga proses fotointesis masih dapat berlangsung dengan baik.

Hasil penelitian tersebut sesuai dengan yang dikemukakan oleh Darmi (2011) bahwa budidaya rumput laut ditambak membutuhkan kedalaman 60- $80 \mathrm{~cm}$ dengan baik karena pada kondisi tersebut matahari masih dapat menembus dasar perairan.

\section{Derajat Keasaman}

Budidaya Gracilaria sp pada stasiun 1 kisaran $\mathrm{pH}$ yang terukur rata-rata berkisar 8,2, pada stasiun 2 ratarata $\mathrm{pH}$ sekitar 9.5 , stasiun 3 diperoleh rata-rata $\mathrm{pH}$ sekitar 8,7. pH yang cocok untuk pertumbuhan Gracilaria sp umumnya berkisar antara 6,2 - 8,2 sedangkan yang optimal adalah 6 - 8. Kandungan derajat keasaman ini masih dalam kisaran sesuai jika ditinjau dari tingkat kesesuaian lahan perairan untuk budidaya Gracilaria sp. dibawah kadar kritis tersebut, maka laju pertumbuhan sel akan menurun (Badruddin dkk, 2014). Kandungan derajat keasaman ini masih dalam kisaran sesuai jika ditinjau dari tingkat kesesuaian lahan perairan untuk budidaya Gracilaria sp. dibawah kadar kritis tersebut, maka laju pertumbuhan sel akan menurun.

\section{Salinitas}

Kisaran salinitas yang diperoleh pada penelitian tersebut masih pada kisaran salinitas yang mendukung pertumbuhan dan perkembangan budidaya rumput laut gracillaria di tambak, hal ini juga dipertegas bahwa Salinitas yang baik untuk budidaya rumput laut gracillaria berkisar antara 15 - 30 ppt dimana kadar garam optimal adalah 20 - 25 ppt. Untuk memperoleh perairan dengan kondisi salinitas tersebut harus dihindari lokasi yang berdekatan dengan muara sungai (Ditjenkanbud, 2006)

\section{Oksigen Terlarut}

Dari hasil pengukuran kandungan oksigen terlarut (DO) setiap stasiun didapatkan rata-rata pada stasiun 1 
sekitar 7,07 mg/l, stasiun 2 rata-rata $6,78 \mathrm{mg} / \mathrm{l}$ dan pada stasiun 3 diperoleh rata-rata kandungan oksigen terlarut sekitar 7,66 mg/l. Kandungan oksigen terlarut yang diperoleh pada setiap stasiun cenderung lebih rendah di banding kandungan oksigen yang dibolehkan untuk kegiatan budidaya perikanan, yaitu 4-5 $\mathrm{mg} / \mathrm{L}$ karena baku mutu oksigen terlarut yang dibolehkan oleh aturan pemerintah RI no 20 Th. 1990 adalah tidak kurang dari 3 $\mathrm{mg} / \mathrm{L}$. Oksigen merupakan gas yang penting di alam karena dibutuhkan dalam proses respirasi atau pernafasan, baik untuk kehidupan maupun proses kimiawi atau perubahan di dalam perairan.

\section{Karbon Dioksisa}

Hasil titrasi yang diperoleh pada saat penelitian diperoleh konsentrasi kandungan karbon dioksida yang rendah stasiun 1 rata-rata sekitar $5,32 \mathrm{mg} / \mathrm{l}$, pada stasiun 2 didapat konsentarsi $\mathrm{CO}_{2}$ rata-rata sekitar $13,98 \mathrm{mg} / \mathrm{l}$ dan pada stasiun 3 diperoleh rata-rata sekitar 16,64 mg/l. Keberadaan $\mathrm{CO} 2$ cukup sulit untuk dideteksi dalam perairan karena langsung dimanfaatkan oleh rumput laut untuk berfotosintesis.Hal ini sesuai dengan pendapat Ruslaini dan Iba (2011), yang menyatakan bahwa CO2 di perairan sulit terdeteksi karena $\mathrm{CO} 2$ segera terpakai atau diserap oleh organisme tanaman termasuk fitoplankton saat berlangsungnya fotosintesis pada siang hari. Konsentarsi karbon dioksida dalam tambak pada semua stasiun tersebut masih dalam konsentarsi yang belum mematikan bagi organisme perairan hal ini dipertegas oleh (Soeseno, 1995) bahwa Kebanyakan spesies biota perairan masih dapat hidup pada perairan yang memiliki kandungan $\mathrm{CO}_{2}$ bebas $60 \mathrm{mg} / 1$. Kadar $\mathrm{CO}_{2}$ bebas tidak boleh mencapai batas yang mematikan (lethal). Kadar $20 \mathrm{mg} / 1$ sudah merupakan racun bagi ikan.

\section{Nitrat}

Unsur hara merupakan salah satu faktor yang berperanan penting dalam mendukung proses metabolisme, pertumbuhan dan kelansungan hidup organisme. Kadar nitrat yang didapatkan selama penelitian adalah pada stasiun 1 diperoleh rata-rat $0,28 \mathrm{ppm}$, pada stasiun 2 didapat rata-rata kandungan $\mathrm{NO}_{3}$ sekitar 0,28 ppm, pada stasiun3 rata-rata sekitar $0,27 \mathrm{ppm}$. Kandungan nitrat tersebut masih dalam batas toleransi untuk untuk kehidupan organisme. Menurut Hendrajat (2010), kadar nitrat yang baik untuk budidaya rumput laut Gracilaria $s p$. adalah $0,1-4,5 \mathrm{ppm}$. Nitrat dapat terbentuk karena tiga proses, yakni badai listrik,organisme pengikat nitrogen, dan bakteri yang menggunakan amoniak. Peningkatan konsentrasi amoniak disebabkan adanya peningkatan pembusukan sisa tanaman atau hewan (Kangkan, 2006).

\section{Phosfat}

Kandungan phosfat di tambak Kecamatan Sinjai Utara pada penelitian diperoleh kandungan fosfat seperti pada stasiun 1 diperoleh rata-rata kandungan fosfat $0,06 \mathrm{ppm}$, pada stasiun 2 diperoleh rata-rata sekitar 0,04 ppm danpada stasiun 3 rata-rata kandungan phosfat yang didapat sekitar $0,03 \mathrm{ppm}$

Kandungan fosfat pada semua stasiun masih optimal, sejalan dengan pendapat Hendrajat (2010) bahwa kadar fosfat yang optimal untuk budidaya rumput laut Gracilaria $s p$. berkisar antara $0-1 \mathrm{ppm}$ untuk tingkat kesuburan tinggi berkisar antara $0,051-1 \mathrm{ppm}$.
Dengan melihat dinamika parameter fisika, kimia air yang diamati di tambak Kecamatan Sinjai Utara. Selanjutnya dilakukan perhitungan matriks kelayakan lahan berdasarkan analisis parameter dilapangan kemudian dibandingkan dengan nilai kisaran parameter yang optimal pada tingkatan kelas kelayakan lahan.

Tabel 3. Hasil analisis kelayakan lahan di Tambak Kecamatan Sinjai Utara untuk budidaya rumput laut.

\begin{tabular}{c|c|c|c}
\hline Stasiun & Nilai yang di peroleh & Hasil & Keterangan \\
\hline 1 & 63 & S2 & Cukup layak \\
2 & 56 & S2 & Cukup layak \\
3 & 63 & S2 & Cukup layak \\
\hline \multicolumn{2}{l}{ Sumber : Data yang telah di olah }
\end{tabular}

Hasil nilai perhitungan matriks kelayakan lahan tambak di Kecamatan Sinjai Utara untuk budidaya rumput laut Gracilaria sp diketahui bahwa pada stasiun I yakni tambak yang dekat dengan laut cukup layak dengan nilai 63. Stasiun II yang berdekatan dengan pemukiman penduduk dengan nilai 56. Stasiun III yang berdekatan dengan persawahan mendapatkan nilai 63. Ketiga stasiun masuk dalam kategori "cukup layak".

\section{KESIMPULAN}

Hasil dan pembahasan seperti yang telah di uraikan di atas maka dapat di simpulkan bahwa kegiatan budidaya rumput laut Gracillaria sp cukup layak untuk dikembangkan di Kecamatan Sinjai Utara.

\section{DAFTAR PUSTAKA}

Abdan, Abdul Rahman dan Ruslaini. 2013. Pengaruh Jarak Tanam Terhadap Pertumbuhan dan Kandungan Karagenan Rumput Laut (Eucheuma spinosum) Menggunakan Metode Long Line. Jurnal Mina Laut Indonesia 03(12): 133-132

Anggadireja JT, Zatnika A, Purwoto H, Istini S. 2008. Rumput Laut: Budidaya, Pengolahan dan Pemasaran Komoditas Perikanan Potensial. Jakarta: Penebar Swadaya.

Anonim, 2007.Materi Pelatihan Budidaya Rumput Laut. Dinas Kelautan dan Perikanan Propinsi Sulawesi Selatan.Makassar .

Badruddin, Boedi, S.J. 2014. Better Management Practices. Seri Panduan Perikanan Skala Kecil. Budidaya Rumput Laut Gracillaria sp di Tambak. WWF Indonesia

Darmi, 2011 Strategi Pengembangan Usaha Budidaya Rumput Laut (Kappapycusalvarezii) Berkelanjutan Di Kabupaten Barru, skripsi.

Dinas Perikanan Kabupaten Sinjai, 2017. Statistik Kelautan dan Perikanan Kabupaten Sinjai.

Ditjenkan Budidaya, 2006.Petunjuk Teknis Budidaya Laut: Rumput Laut

Hendrajat EA, Pantjara B, Mangampa M. 2010. Polikultur udang vaname (Litopenaeus vannamei) dan rumput laut (Gracilaria verrucosa).Forum Inovasi Teknologi Akuakultur: 2010; Maros, Indonesia (ID): Balai Riset Perikanan Budidaya Air Payau.

Kangkan A.L. 2006. Studi Penentuan Lokasi untuk Pengembangan Budidaya Laut Berdasarkan Parameter Fisika, Kimia dan Biologi di Teluk Kupang, Nusa 
Tenggara Timur. Tesis. Universitas Diponegoro, Semarang.

Nurdin, I.N. 2012.Evaluasi Mutu dan Penanganan Pascapanen Rumput Laut Eucheuma cottonii di Kabupaten Buton Provinsi Sulawesi Tenggara.Tesis Program Pasca Sarjana Fakultas Teknologi Pertanian Universitas Gadjah Mada.

Ruslaini dan W. Iba. 2011. Studi Kondisi Kualitas Air Budidaya Rumput Laut (Gracilaria verrucosa) pada Tambak Tanah Sulfat Masam (Studi Kasus di Kecamatan Moramo, Kabupaten Konawe Selatan, Provinsi Sulawesi Tenggara). Aqua Hayati. 7(3): 189 195.

Septiawan, A.D. 2009. Pertumbuhan dan Jumlah Rendemen Agar Rumput Laut Gracilaria verrucosa (Hudson) Papenfuss pada Kerapatan yang Berbeda. Skripsi. Jurnal. Biologi Fakultas Sains dan Matematika Univ.Diponegoro, Semarang

Sugiyanto., Munifatul, I., Erma, P. 2013. Manajemen Budidaya dan Pengolahan Pasca Panen Gracilaria verrucosa (Hudson) Papenfus. Study Kasus : Tambak Desa Mororejo, Kecamatan Kaliwungu, Kabupaten Kendal. Jurnal Manajemen Budidaya dan Pengolahan 14(2): 42-50.

Zatnika, A. 2009. Pedoman Teknis Budidaya Rumput Laut. Badan Pengkajian dan Penerapan Teknologi. Jakarta. 